\title{
New Approaches to the Concept of the Knowledge in Chinese Philosophy of the second Half of the Twentieth Century
}

\author{
Valery A. Kiselev \\ Candidate of Science in Philosophy, associate Professor \\ People's Friendship University of Russia (RUDN \\ University), 6 Miklukho-Maklaya St., Moscow, 117198, \\ Russian Federation \\ E-mail: valery.kiselev@gmail.com
}

\author{
Varvara I. Chernykh, PhD student \\ People's Friendship University of Russia (RUDN \\ University), 6 Miklukho-Maklaya St., Moscow, 117198, \\ Russian Federation \\ E-mail: onufrieva.varvara@yandex.ru
}

Olga S. Nimenskaya, PhD student

People's Friendship University of Russia (RUDN University), 6 Miklukho-Maklaya St., Moscow, 117198, Russian Federation E-mail: ocsafronova@mail.ru

\begin{abstract}
This article examines the new approaches to the concept of knowledge in modern Chinese philosophy. Upon acquaintance with Western philosophy, Chinese thinkers began to use Western methodological concepts to interpret classical ideas of Chinese thought. One of the striking example of such synthesis is the philosophy of Boston Confucianism, which rethinks Confucian concept of knowledge by using pragmatic and semiotic tools.
\end{abstract}

Keywords-Chinese philosophy; Confucianism; Knowledge; epistemology; Boston Confucianism

\section{INTRODUCTION}

Since ancient times, Chinese culture has demonstrated a respectful attitude towards knowledge. Confucius, who is often referred to as the "first teacher", paid considerable attention to knowledge and education. One of the basic books of Confucianism, "Analects", begins with the statement "The Master said, To learn and at due times to repeat what one has learnt, is not that a pleasure after all?" [1. I, 1]. In the earliest period of Confucianism, an understanding of knowledge was formed not simply as the result of cognitive ability, or the amount of knowledge or all the cognitive perceptions about the surrounding reality. In Confucius teachings, knowledge was usually perceived as a way to achieve virtue, the practical way to live a good life, which leads to achieving virtue as part of person's behavior. Knowledge was not the abstract reasoning, but the activity aimed to achieve practical result.

Knowledge was directed to the past, culture acted as a repository of the sages' actions of antiquity and the most important historical facts. At the same time, knowledge maintained not only continuity with the wise men of antiquity, strengthened the tradition, but is also served as the means of developing innovations. Knowledge and, accordingly, the use

The article was prepared in frames of the Project № 100335-0- 000 «Knowledge, Mind and Faith in Historical and Philosophical Discourse: Comparative Studies» of ancient models did not mean the simple repetition, but rather served as an example to create the new meanings in a changed social reality.

In the late 19th - early 20th centuries, China faced the unprecedented pressure from the Western culture. At that time, Chinese intellectuals made the acquaintance with Western philosophy and since then, while maintaining the crucial role of knowledge in the intellectual culture of China, views on the ideal of knowledge have evolved by using Western cognitive concepts [2. P. 24-33]. In the Chinese thought, the greatest influence on the development of knowledge concepts in the 20th century was provided by the philosophical concepts of I. Kant and the ideas of American pragmatism.

\section{SEVERAL VIEWS ON The FeAtures OF THE CONCEPT OF KNOWLEDGE IN CHINESE PHILOSOPHY}

On the example of philosophical utterances recorded in Confucius' "Analects", French sinologist François Jullien explains that Confucianism does not seek to define general concepts, builds any rigorous theories, and does not offer mystical "revelations." In his studies, Jullien concludes, that the object of Confucius's efforts is not the knowledge, as it may seem; it is not to focus on seeking the truth, but the regulation of behavior, that allows us to assimilate the order reigning in the world. In the treatise, the wisdom itself is realized by means of "Heaven" - the spiritual power of Confucianism, which was recognized as the supreme deity, strict and oriented towards virtue. In general, the Chinese discourse, according to Jullien, does not unfold against the backdrop of the otherworldly, it has no horizon of "Truth" [3. P. 245] in its Western sense.

Interesting notion, that the modern French researcher - J.-C Pastor, discussing the issue of knowledge in Confucianism (especially in neo-Confucianism), comes to the conclusion that 
the moral consciousness, first of all, is an innate and immediate reality, which is brought into action by the conscience of man. Thus, in to "know your fundamental character", that is, in order to experience genuine self-embodiment, the subject must go deep into his consciousness "xin" (心, heart) and "exhaust his nature". Such an inner transformation and moral exercise, according to J.-C. Pastor is the "metaphysical" and "mystical" dimension, where the intuitive approach plays an important role, through which a person finally achieves a state of awareness that allows the mind to merge with the universe in "unceasing birth" [4. P. 245].

Concerning the transfer of knowledge, another French sinologist J. Thoraval notes that since ancient times the special training institute within the framework of the old neoConfucian school (shuyuan, 书院 - academy, higher school) has existed in China. Teachers in that kind of schools conducted, first of all, the practical teaching of the behavioral principles in the general life experience, and there was no transfer of abstract or impersonal knowledge. Drawing an analogy with Europe, Thoraval notes that in time of German philosopher Schelling Germany was far from that kind of moral upbringing. Thus, European intellectual intuition is considered as, firstly, an act - it is no more than knowledge transmitted through the usual channels of theoretical education, and in Chinese culture it is a basis to bring up the practical moral virtue [5. P. 236].

\section{Boston CONFUCIANISM AS SYNTHESIZING CHINESE \\ TRADITION AND PRAGMATISM: CONCEPT OF KNOWLEDGE}

"Boston Confucianism" pays much attention to the problem of knowledge in synthesis of the Chinese tradition with Western philosophy.

Boston Confucianism considers Confucian ethics as a living tradition, dating back to the days of Confucius. In their views, they, on the one hand, rely on traditional Confucian treatises, on the other - Confucian traditions are viewed from the angle of the philosophical tools of the Western thought, in particular, pragmatism. In the question of knowledge, the attention of researchers is transferred from the epistemological (cognitive) component of human nature, to the way in which the process of cognition has a direct effect on the person himself and how he "cultivates" himself $[6,7]$. The emphasis shifts from the cognitive capabilities of the subject to his axiological and ethical perception of reality. The roots of this campaign can be traced in early Confucianism, for example, in the "Analects" it is said: "The Master said, a knight whose heart is set upon the Way, but who is ashamed of wearing shabby clothes and eating coarse food, is no worth calling into counsel" [1. IV, 9].

Boston Confucians are working on to "re-interpret" and rethink Confucian values, primarily in order not only to popularize and re-revive the Confucian tradition and fuel the interest in it as a possible implementation in practice, drawing a retrospective view on the values that were still designated by Confucius (humanity, ritual decency), but also to allow it to harmoniously integrate into the global sociocultural stratum.
Speaking specifically about the concept of knowledge in ideas of Boston Confucians we can note that, on the one hand, they do not deny the subject's ability to cognize in principle at all, but consider that any knowledge that a person receives is the subject that is to be corrected [8]. Thus, "Boston Confucians" make reference to the tradition of C. Pierce and $\mathrm{J}$. Dewey. According to them, the knowledge, like the possession of a mental picture, is subordinated to learning, as a correction for representations that direct the interactionism [9. P. 303]. In addition, according to one of the researches of Boston Confucianism, R.K. Neville, training "is perhaps the most effective way to implement governance, since it consists in helping people to find ways to manage their own habits ..." [6. P. 27].

R.K. Neville and another researcher - Tu Wei-ming recognize that any human experience can be perceived as "fundamentally supportive" to the values of the person himself, if to some extent this experience has an impact on the original goal, whether it is the knowledge of the world as a whole, or the search for truth [6. P. 27]. At the end, any experience will be included in the "database" of a person and it can be used in life if it does not contradict either the values of the cognizing person or the values of the people around him, since, in many ways, his behavior proceeds from certain "layers" of values: family, social status, society. This can be interpreted as follows: any human experience, whether it is positive or negative, will become the experience that can be applied in human everyday life, and it will not contradict either the values of the person or the values all the people share around him, on condition that this experience affects the initial goal of the person (cognition, search for truth, seeking knowledge etc.)

Another important point the Boston Confucians took from the pragmatism of C.S. Pierce, dwells upon the notion that representations are not the mental phenomena, but habits of interpreter behavior [6. P. 304]. Habits have two important links. On the one hand, pragmatism shows how habits are related to phenomena, which interpreters interact with, including the physical world, social structures and other people as interpreters of the phenomena. Habits are inextricably linked to the goals of the person, from which the interactions derive their leadership. The Interpretations have many functions. In rare cases, their goals are simple and understandable. However, for the most part they play only the performative function, serving some other goals that cannot be fulfilled without having the certain view of the world and the understanding how the phenomenon can be achieved. The interpretations of the world in every community and interpreter himself are intricately intertwined with each other and, moreover, forming habits, together constitute the complex life. It should be noted that this trend can be considered as one of the foundations of the Boston thinkers' methodology, based on the theory of signs as the main tool for "reinterpretation" of Confucian values [6. P. 13-14].

Semiotics, or the theory of signs, according to R.K. Neville, analyzes the structures of interrelated interpretations. Interpretations consist of signs that are interpreted, signs as an interpreted object, and signs as habits of interpreting. In addition, since the European theory of signs is focused on the signs as mutually determined, so pragmatic semiotics focuses 
on how signs can manifest themselves in a particular context, how they become determinants or disappear in uncertainty, as some sign systems assume others and changes in one system affect other more or less general systems [10. P. 11-15].

Thus, the pragmatic theory sees any separate interpretation, as prevailing in the vast expanse of other interpretations, a kind of system into the other system; each interpretation has a context, and each interpretation environment can contain an immense number of nodal points - the meanings that carries this or that knowledge or this or that symbol.[2. P. 74-76]

The Pragmatic theory of signs (semiotics) recognizes that the interpretation of certain events extends also in all continuity and breadth. From the interpretation of the environment sensations of the world and its manifestations it widens to the formation of the specific goals and the one's own needs' satisfaction: "When society develops to a complex sign system of high civilization, it has those elements of ritual decency, which Confucius and Xunzi wrote about, - elements that change the interaction of [people in society] so, that it becomes friendship based on mutual trust ... and the concept of procreation [becomes more complicated] so, that it becomes a part of family life based on filial piety, etc. "[10. P. 14]. Therefore, having the knowledge any person gets something new about the world not as the set of facts or the amount of information, but as opportunity to somehow change himself and the world around, knowledge "grows up" and becomes a part of his personality.

According to the statement of the "Bostonians", for the ancient Confucian, it does not matter which sign system bears the functions of ritual decency, since the culture contains several iconic systems that deal with this. With regard to pragmatism, this maxim shows, first, how the signs create a culture of "extra-" and "above-" nature; secondly, how much signs are conditional; thirdly, as the signs of a high culture, harmonious interactions form that the virtues of this high culture are contained [11]. Out of this, we can draw a conclusion about the relationship of reason and faith: whatever belief in the transcendent a person has, it will still be closely intertwined with his knowledge and, if we think ideally, will not contradict his cognition as one of the features of human nature. In knowledge, Boston scholars put not only the context of "knowledge for the sake of knowledge", but also ethical and philosophical - "cognition as self-improvement of one's own "self". In general, the concept of "self-improvement of one's own self" includes two contents: the first of them is going beyond the limits of one's self as a self-determination of the individual, in order to open the self to society and, possibly, build social "spirituality" in society without context of cultural, religious or linguistic affiliation [6. P. 186-190]. The second implies the opposite process: the "cultivation" of a person in his concrete manifestation - taking into account his sexual or ethnic identity, age, religious views, level of education or the language he speaks and thinks [6. P. 186-190]. This is done not to discriminate against these features (racial, ethnic or even gender), but most fully reveal them and through the personal beginning in a person, enrich and cultivate the "spiritual" culture of society as a whole. Unlike a number of other traditions, Confucianism chose the path "in the world", the way here-and-now. "I am a Man among other people of the same kind." [12. P. 170]

\section{CONCLUSION}

In general, we can say that Boston Confucians speaking about the correlation of faith and reason come to the idea that, in the presence of an ethical component, it is possible to build a harmonious combination, with the result as a person who can listen, expand horizons and engage in self-reflection. In addition, neither religious beliefs, nor age, nor other ethnic and cultural differences could become the main obstacle to the full understanding of the world. Moreover, all the above-mentioned differences are an excellent tool for self-realization. In order to understand the world and multinational society better, it is necessary to start with ourselves, transforming our own views of the world into something more than ideology or dogma. Confucian way, according to Boston Confucians, is just an excellent method that facilitates the transformation of all the habits, which are important for the formation of both personal and social qualities. As it is going through these habits and through the semantic contexts that these habits carry in themselves, all human relationships are mediated, including the attitude to yourself as to the "self". As the "self" is a Christian, the "self" is a Chinese, the "self" is a university professor. Moreover, any expansion of the interpretation of certain characteristics of one's own "self" is the receipt and significant expansion of one's own knowledge about oneself, others and about the world.

\section{REFERENCES}

[1] The Analects of Confucius. Trans. by Arthur Waley. - London: George Allen\&Unwin Ltd., 1956.

[2] Kiselev V.A. Formation of History of Chinese Philosophy as Academic Discipline in China. // RUDN Journal of Philosophy. 2017. Volume 21. Number 1.

[3] Jullien F. Detour and Access, Strategies of Meaning in China and Greece (Le détour et l'accès). Moscow: Moscow philosophical fund, 2001.

[4] Pastor J.C. Mou Zongsan (1909-1995) et son recours problématique au taoïsme. // Revue international de philosophie. 2005/2 (№ 232).

[5] Thoraval J. La question de l'intuition intellectuelle et la philosophie confucéenne contemporaine. // Revue international de philosophie. 2005/2 (№232).

[6] Neville R.C. Boston Confucianism: Portable tradition in the late-modern world. - Albany : State University of New York Press, 2000.

[7] Neville R.C. Reconstruction of Thinking: Axiology of Thinking. Albany : State University of New York Press, 1981.

[8] Tu Wei-ming. Humanity and self-cultivation: Essays in Confucian thought. - Berkeley: Asian Humanities Press, 1979.

[9] Pierce C.S. Selected works. - Moscow: Logos, 2000

[10] Ritual and Deference: Extending Chinese Philosophy in a comparative Context. Ed. Roger T. Ames. - Albany : State University of New York Press, 2008.

[11] Chernykh V.I. The Pragmatism and Semiotics as the Basic Methology in the Boston School of New Confucianism // Journal Space and Time. 2016. №1-2(23-24).

[12] Tu Wei-ming. Centrality and Commonality: an essay on Confucian religiousness. Ed. Roger T. Ames. Albamy: State University of New York Press, 1989. 